\title{
CHARACTERIZATION OF ALGINATE PREPARED FROM BROWN SEAWEEDS IN THUA THIEN-HUE PROVINCE, VIETNAM
}

\author{
Tran Vinh Thien
}

Department of Chemistry and Biology, Phu Yen College of Pedagogy, Vietnam

\section{Chu Dinh Kinh*}

Institute of Chemistry, Vietnamese Academy of Science and Technology

Tran Thai Hoa, and Dinh Quang Khieu

Department of Chemistry, College of Sciences, Hue University, Vietnam

Received 02 April 2007

\begin{abstract}
The characterization of alginate prepared from brown seaweeds in TT-Hue province of Vietnam was investigated. Composition and the sequential structure of alginate were determined by ${ }^{1} \mathrm{H}$ NMR, ${ }^{13} \mathrm{C}$-NMR, TOCSY, ${ }^{1} \mathrm{H}-{ }^{1} \mathrm{H}$ COSY, and ${ }^{1} \mathrm{H}^{-13} \mathrm{C}-\mathrm{HSQC}$ spectrum. It is found that alginate with molecular weight around $101 \mathrm{KDa}$ is composed of homopolymeric regions of $\mathrm{M}$ and $\mathrm{G}$ blocks, interspersed with very small amount of regions of alternating structure of MG block. This information is essential for application guideline of alginate in TT-Hue province.
\end{abstract}

\section{INTRODUCTION}

Alginate, a family of non-branched binary copolymers of 1-4 glycosidically linked $\beta$-Dmannuronic acid $(\mathrm{M})$ and $\alpha$-L-guluronic acid residues can be considered as patterns of homopolymeric blocks of $\mathrm{G}$ and $\mathrm{M}$, respectively, and blocks with an alternating sequence, all in coexistence. Alginate contains all four possible glycosidic linkages: diequatorial (MM), diaxial (GG), equatorial-axial (MG), and axial-equatorial (GM) [1]. Chemical block structures of alginate are presented in Fig. 1.

It has been known that the physical properties of alginates depend on the relative proportion of four types of blocks. The industrial utilization of any particular alginate will depend on its properties and therefore on its uronic acid composition, however, the composition and sequential structures of alginate of different resource are different from one place to others. From a scientific point of view, the uronic acid composition of alginate from different sources had to be examined. ThuaThien-Hue province is the zone in which some brown seaweed species are mainly distributed with the yield estimated in wet state to be about 3,000 metric tons per year [2]. Attempts to study on the brown seaweed have been made so far. Vo Thi Mai Huong et

\footnotetext{
*Corresponding author e-mail: mailto:kinhcd@ich.ntsc.vn
} 
al $[3,4]$ investigated the technology of alginate extraction from sargasssum of TT Hue and some of their bio-physical and bio-chemical specifications. However, no single paper studying on the composition and the sequential structure of alginate extracted from brown seaweeds in TT-Hue has been reported so far. In previous papers [5 - 7], the authors demonstrated the use of the second order orthogonal design in the extract of sodium alginate from brown seaweeds in TTHue province. The desired quality of alginate can be obtained from appropriate technology regimes based on regression equations. In the present work, the characterizations of obtained alginate are discussed.

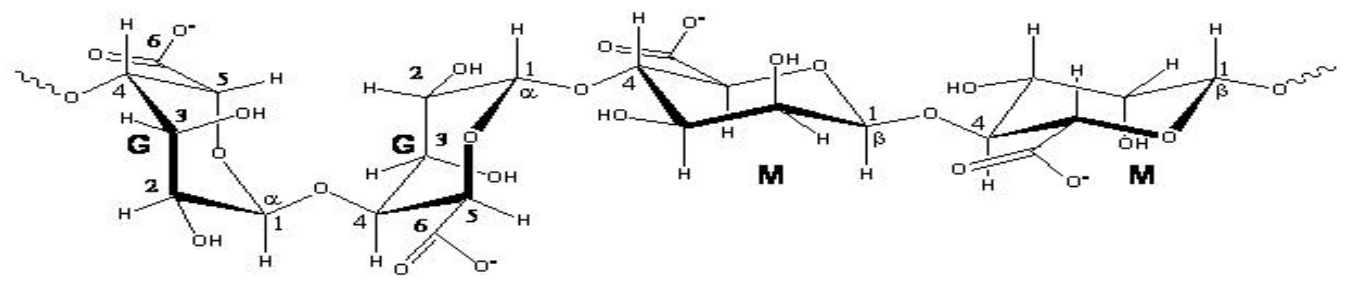

Fig. 1: Chemical block structures of alginate.

\section{EXPERIMENTAL}

Alginate was prepared from the brown-seaweed of TT-Hue in the manner described in the previous paper [5 - 7]. The viscosity average molecular weight of alginate was calculated using classical Mark-Houwink equation: $[\eta]=K . M_{v}^{\alpha}$, where $[\eta]$ is the intrinsic viscosity of alginate. The intrinsic viscosity of alginate in $0,1 \mathrm{M} \mathrm{NaCl}$ solution were measured in triplicate for each of six different concentrations by recording the efflux time of the solution in Ubbelohde viscometers maintained in a constant-temperature water bath at $25 \pm 0.2^{\circ} \mathrm{C} . \mathrm{K}=7 \cdot 3 \cdot 10^{-5}$ and $\alpha=$ 0.92 are constants for given solute-solvent system and temperature $[8,9]$. The obtained alginate was characterized by ${ }^{1} \mathrm{H}-\mathrm{NMR},{ }^{13} \mathrm{C}-\mathrm{NMR},{ }^{1} \mathrm{H}-{ }^{1} \mathrm{H}$ TOCSY (TOal Corelated SpectrometrY), COSY (Correlated SpectrometrY), HSQC (Heteronuclear Single Quantum Correlation) using Bruker Advance $500 \mathrm{MHz}, \mathrm{NaOD} 5 \%$ solution in $\mathrm{D}_{2} \mathrm{O}$ were used as the solvent. The carbon atoms in mannuronate and guluronate residues are denoted and named as G1, G2, G3, G4, G5, G6, M1, M2, M3, M4, M5 and M6 as shown in Fig. 1.

\section{RESULTS AND DISCUSSION}

The resultant calculation of the viscosity average molecular weight showed that the viscosity average molecular weight of alginate is around $101 \mathrm{KDa}$ as shown in Table 3. Fig 2 shows ${ }^{1} \mathrm{H}-$ NMR of sodium alginate. ${ }^{1} \mathrm{H}-\mathrm{NMR}$ spectrum of alginate consists of ten peaks in correspondence to 10 proton resonances of mannuronate and guluronate. Two peaks of 5.473 and $5.090 \mathrm{ppm}$ located at the lowest magnetic field side should be assigned to G1 hydrogen and M1 hydrogen, respectively because of the strongest deshielding by two oxygen atoms adjacent to them and the deshielding by oxygen atom from axial linkage is stronger than that by oxygen atom from equatorial linkage. From TOCSY spectrum as shown in Fig 3, it could be seen that G1 hydrogen interacts with the protons of G5, G4, G3, and G2 at 4.883, 4,571, 4.446, 4.318 ppm. Among them, the interaction signal of G1 and the other proton at $4.883 \mathrm{ppm}$ is the smallest so the peak at $4.883 \mathrm{ppm}$ should be attributed to G5. In order to interpret the neighboring proton of G1, the ${ }^{1} \mathrm{H}-{ }^{1} \mathrm{H}$ COSY of alginate has been performed (Fig. 4). G1 hydrogen only interacts with the proton at $4.318 \mathrm{ppm}$. Then the peak at $4.318 \mathrm{ppm}$ should be assigned to G2 hydrogen. In turn, $\mathrm{G} 2$ hydrogen interacts with the proton located at $4.446 \mathrm{ppm}$. The peak at $4.446 \mathrm{ppm}$ is the resonance signal of G3 hydrogen. The rest of $4.571 \mathrm{ppm}$ is G4 hydrogen. In the same manner, 
the TOCSY spectrum confirms that M1 hydrogen interacts with the protons having resonance signals of 4.446, 4.318, 4.152, $4.135 \mathrm{ppm}$. From COSY spectrum, the peak at $4.446 \mathrm{ppm}$ resulted in interaction of M1 should be attributed to the proton of M2. Referring back to TOCSY spectrum, in addition with the interaction of proton of M2, M1 proton interacts with two protons at 4.152 and $4.318 \mathrm{ppm}$. Two these peaks should be assigned as the protons of M3 and M4. On the other hand, the interaction of M2 with the proton at $4.152 \mathrm{ppm}$ is observed in COSY spectrum. As resulted, the resonance signal at $4.152 \mathrm{ppm}$ is obviously of M3 hydrogen.
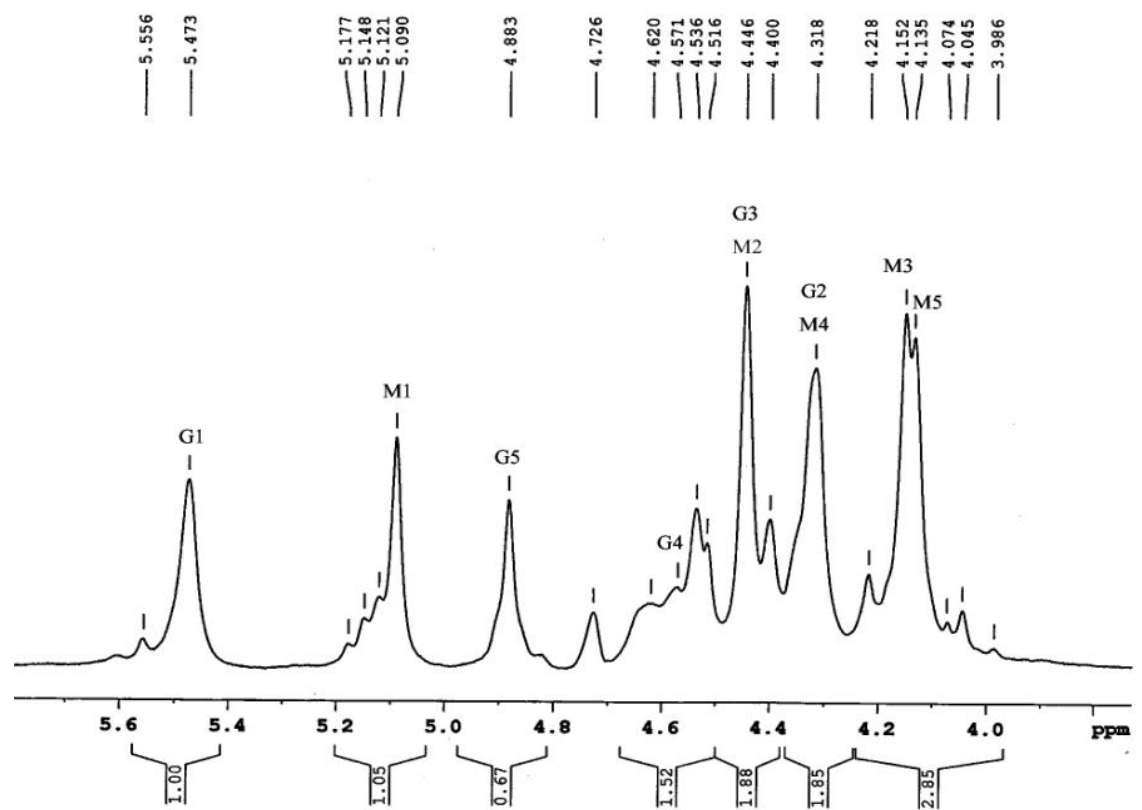

Fig. 2: ${ }^{1} H-N M R$ of alginate.

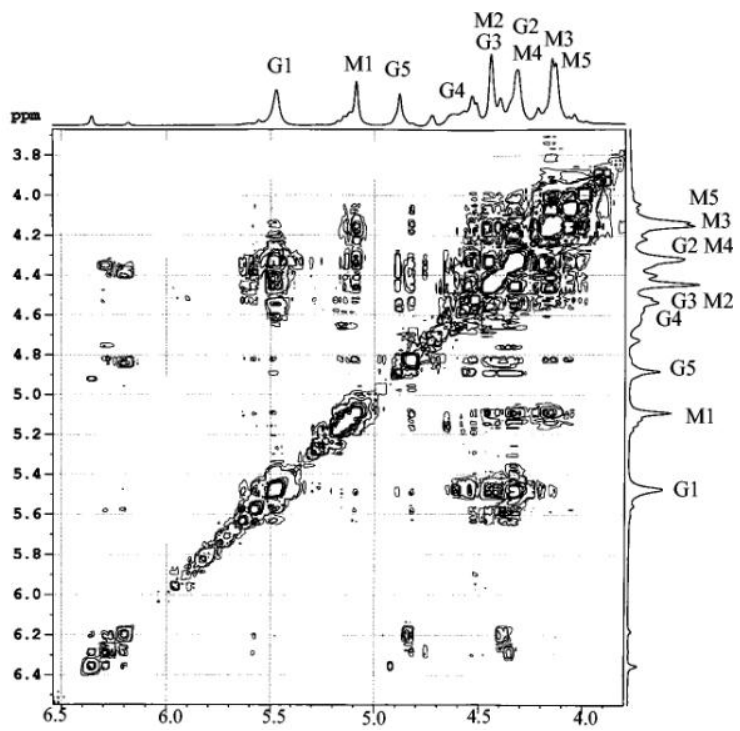

Fig. 3: TOCSY spectrum of alginate. 


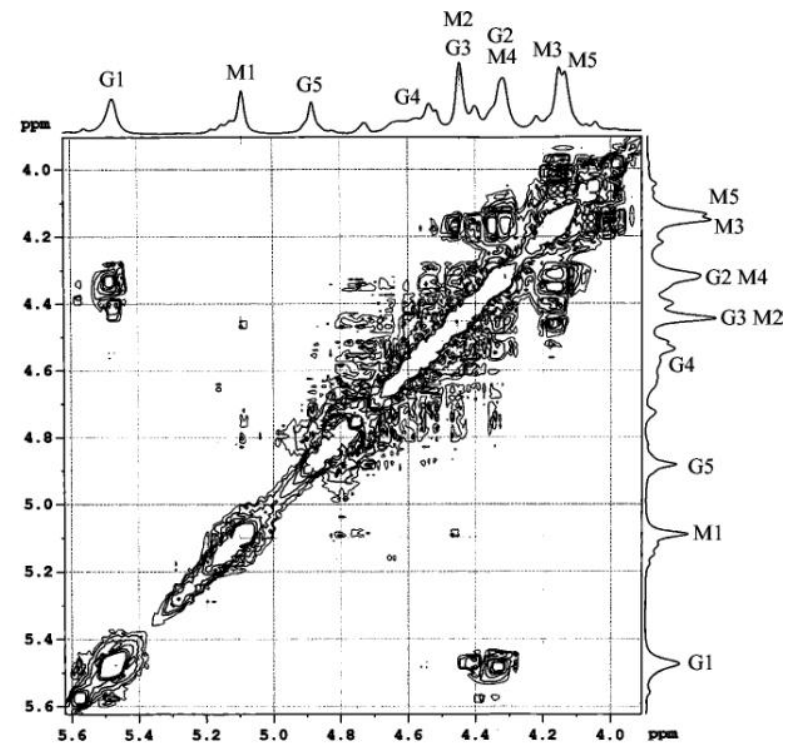

Fig. 4: COSY spectrum of alginate.

The rest of $4.318 \mathrm{ppm}$ is assigned to M4 hydrogen. In both COSY and TOCSY spectrum, it could be seen that M4 proton interacts with the other proton at the highest field and consequently, the signal at $4.135 \mathrm{ppm}$ is certainly of M5. The resultant assignment of alginate peaks is listed on Table 1 and Fig. 2 . However, ${ }^{1} \mathrm{H}-\mathrm{NMR}$ could not provide information of MG and GM blocks so the ${ }^{13} \mathrm{C}-\mathrm{NMR}$ was performed.

Table 1: Chemical shift of protons of D-mannuronic acid $(M)$ and L-guluronic acid $(G)$.

\begin{tabular}{lccccc}
\hline \multicolumn{1}{c}{ Acid } & H1 & H2 & H3 & H4 & H5 \\
\hline D-mannuronic acid (M) & 5.090 & 4.446 & 4.152 & 4.318 & 4.135 \\
L-guluronic acid (G) & 5.473 & 4.318 & 4.446 & 4.571 & 4.883 \\
\hline
\end{tabular}

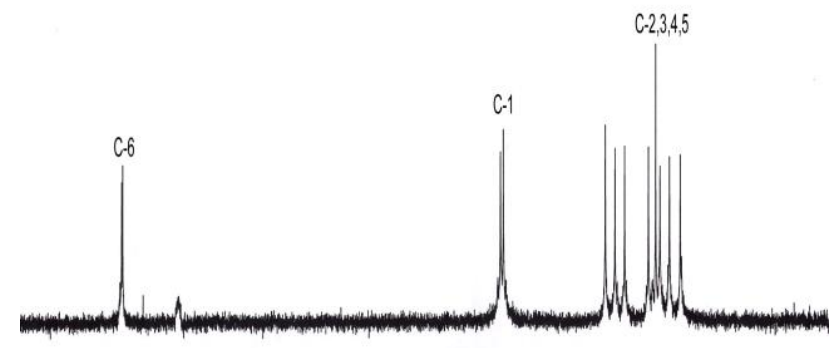

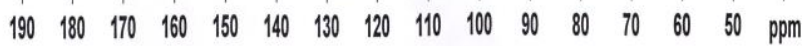

Fig. 5: ${ }^{13}$ C-NMR spectrum of alginate.

${ }^{13} \mathrm{C}-\mathrm{NMR}$ of alginate consists of 12 peaks as shown in Fig. 5. Two peaks of 175.58 and 175.38 ppm at the lowest magnetic field should be contributed to carbons of G6 and M6 due to the 
strongest deshielding of two oxygen atoms of carboxyl group. For identifying the other peaks of ${ }^{13} \mathrm{C}-\mathrm{NMR},{ }^{1} \mathrm{H}-{ }^{13} \mathrm{C}$ HSQC spectrum was performed. Fig 6 shows ${ }^{1} \mathrm{H}-{ }^{13} \mathrm{C}$ HSQC of alginate. Drawing horizontal lines from identified peaks of ${ }^{1} \mathrm{H}-\mathrm{NMR}$ and vertical lines from peaks of ${ }^{13} \mathrm{C}$ NMR, resonance signals of corresponding carbons are listed in Table $2 .{ }^{13} \mathrm{C}$ NMR spectrum of $\mathrm{C}-1$ carbons is shown in Fig. 7. C-1 carbons of mannuronate and guluronate show peaks in the range of 100-102 ppm, and each peak is separated owing to the vicinal residue bonded with carbon. MG, GG, MM and GM in the order from lower magnetic field side should have been observed [10]. In that case, only two peaks around $101 \mathrm{ppm}$ was obtained. The question is whether these two peaks are assigned to (MG-GG), (GG, MM), or (MM-GM) or not.

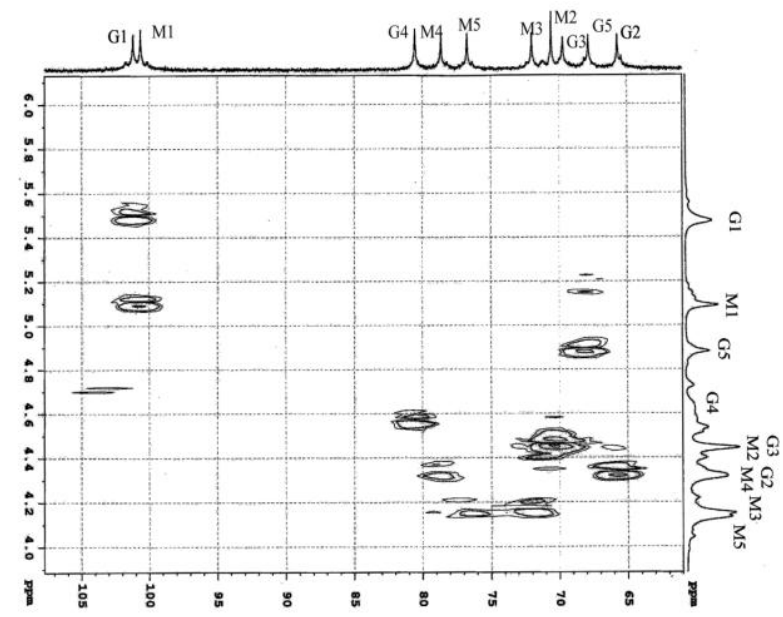

Fig. 6: ${ }^{1} \mathrm{H}-^{13} \mathrm{C} H S Q C$ spectrum of alginate.

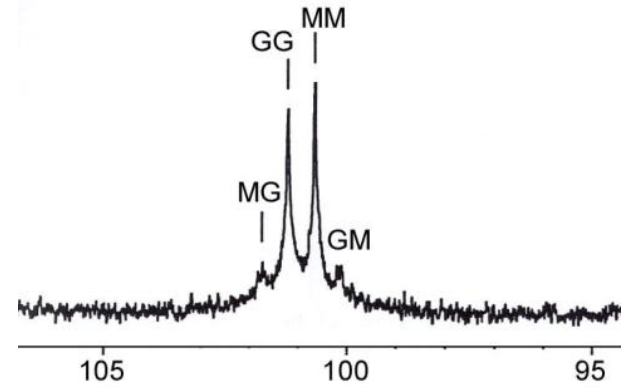

Fig. 7: ${ }^{13} C-N M R$ spectrum of $C 1$ carbons.

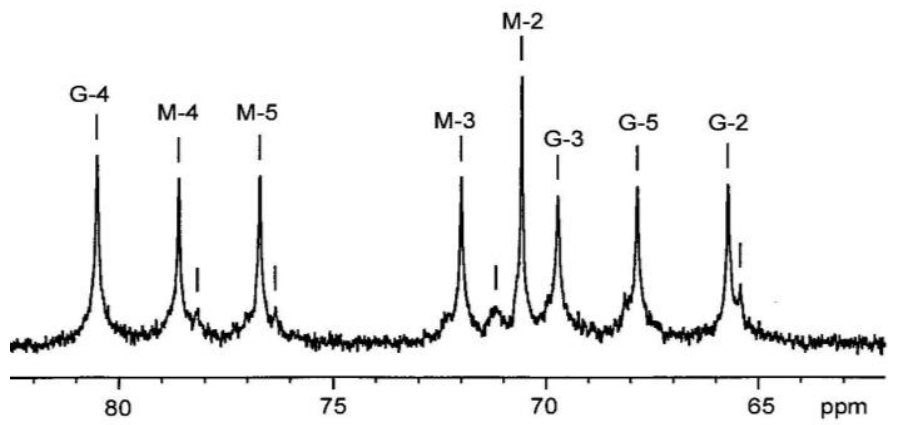

Fig. 8: ${ }^{13} C-N M R$ spectra of alginate in C2-C5 region. 
Referring back to Fig. 3, the resonance signals of the protons of M1 and G4 and the protons of M4 and G1 also were not observed suggesting that two peaks of 101.22 and $100.66 \mathrm{ppm}$ should correspond to MM and GG as shown in Fig 7. Peaks of C-2,3,4 and C-5 is shown in Fig 8. The single peak at $78.62 \mathrm{ppm}$ corresponding to M-4 carbon indicates that the vicinal residues bonded with M-4 are mainly mannuronic acid; therefore mannuronic acid may form homopolymeric structure.

Table 2: Chemical shift of protons of D-mannuronic acid $(M)$ and L-guluronic acid $(G)$.

\begin{tabular}{lcccccc}
\hline \multicolumn{1}{c}{ Acid } & C1 & C2 & C3 & C4 & C5 & C6 \\
\hline D-mannuronic acid (M) & 100.66 & 70.59 & 72.01 & 78.62 & 76.72 & 175.38 \\
L-guluronic acid (G) & 101.22 & 65.74 & 69.74 & 80.53 & 67.86 & 175.58 \\
\hline
\end{tabular}

Similarly, guluronic acid may form homopolymeric structure. Peaks around 100.5 and 100.2 ppm of GM and MG are very small but visible which demonstrates that GM and MG blocks are very shorter in comparison with homogeneous blocks. The amount ratio of mannuronic acid and guluronic acid (M/G ratio) in the alginate and the fraction of MM block and GG block are calculated by integrated areas of $\mathrm{H} 1$ of $\mathrm{M}$ and $\mathrm{G}$. These values are also determinated by the intensities of carbon M1 and G1 but it isn't certain result. The resultant calculations are shown in Table 3. The unequivalent amount of $M$ and $G$ as seen in Table 3 can be contributed to negligible amounts of MG and GM block. It is concluded that the obtained alginate is composed of chains of homopolymeric block $\mathrm{M}$ and $\mathrm{G}$ in which chain of block $\mathrm{M}$ is longer, interspersed with very small amounts of regions of alternating structure of MG block.

Table 3: Chemical characteristics of alginate.

\begin{tabular}{ccccc}
\hline \multirow{2}{*}{$\begin{array}{c}\text { The viscosity average } \\
\text { molecular weight of } \\
\text { alginate (kDa) }\end{array}$} & \multicolumn{2}{c}{ M/G ratio } & \multicolumn{2}{c}{ Fraction blocks (using ${ }^{\mathbf{1}} \mathbf{H}-\mathrm{NMR}$ ) } \\
\cline { 2 - 5 } & Using ${ }^{1} \mathrm{H}-\mathrm{NMR}$ & Using ${ }^{13} \mathrm{C}-\mathrm{NMR}$ & $\% \mathrm{MM}$ & $\% \mathrm{GG}$ \\
\hline 101 & 1.05 & 1.15 & 51.22 & 48.78 \\
\hline
\end{tabular}

\section{CONCLUSION}

This is the first study on the structure of alginate prepared from brown seaweeds in TT-Hue province. It was found that alginate consists of block copolymers composed of homopolymeric regions of $\mathrm{M}$ and $\mathrm{G}$, interspersed with very small regions of alternating structure of MG block. We hope that this work will be useful for applications of the investigated alginate to agriculture and medicine.

\section{REFERENCES}

1. Dennis J. Mc Hugh (1987), Production and utilization of products from commercial seaweeds, FAO fisheries technical paper, vol. 288, pp. 8-9.

2. Nguyen Huu Dai (1997), Sargassaceae in Viet Nam - Resource \& Utility, Agriculture Publishing House, Ho Chi Minh city, (Vietnamese). 
3. Vo Thi Mai Huong (2000), Some of bio-physical and bio-chemical specifications of brown seaweeds sargassum SP4 seashore growing of Lang Co, TT-Hue province, Journal of Biology, vol. 22, (3b), pp. 73-76 (Vietnamese).

4. Vo Thi Mai Huong and Truong Van Lung (1999), Study on technological extract alginate from sargasum of Thua Thien-Hue, Proceedings of National conference on biological technology, Ha Noi, pp. 556-571 (Vietnamese).

5. Tran Thai Hoa and Tran Vinh Thien (2003), Study on some factors influencing on the preparation process of alginate from brown seaweeds of TT-Hue province, Proceedings of 4th National chemistry conference, Ha Noi, vol. 1, pp. 318-325 (Vietnamese).

6. Tran Thai Hoa and Tran Vinh Thien (2004), Study on preparation of oligoalginate by hydrolysis method, Journal of Research and Development, Department of Sciences and Technology, TT-Hue province, vol. 1(44), pp. $70-76$ (Vietnamese).

7. Tran Thai Hoa, Tran Vinh Thien, and Dinh Quang Khieu (2005), Factorial experimental designs in preparation of alginate from brown seaweeds of Thua Thien-Hue Province, The 2nd International Symposium on Advanced Materials in Asia-Pacific Rim, Ha Noi, pp, 7477.

8. Alistair M. Stephen (1995), Food Polysaccharides and their Application, Food and Technology, vol. 67, pp. 245-248.

9. Anita Martinsen, Gudmund Skjâk-Bræk, Olav Smidsrød (1991), Comparison of different methods for determination of molecular weight and molecular weight distribution of alginates, Carbohydrate Polymers, vol. 15, pp. 171-193.

10. Ikeda, A., Takemura, A., and Ono, H. (2000), Preparation of low-molecular weight alginic acid by acid hydrolysis, Carbohydrate Polymers, vol. 42, pp. 421-425. 